\title{
Multilocular cystic renal cell carcinoma: A case report and review of the literature
}

\author{
JIA HU ${ }^{1-3}$, LU JIN $^{1,3}$, YIFAN LI $^{1,3}$, TAO HE ${ }^{1-3}$, JIAJU LIU $^{1,3}$, BENTAO SHI $^{1,3}$, \\ SHANGQI YANG ${ }^{1,3}$, YAOTING GUI ${ }^{3}$, XIANGMING MAO ${ }^{1,3}$, YONGQING LAI $^{1,3^{*}}$ and LIANGCHAO NI ${ }^{1,3^{*}}$ \\ ${ }^{1}$ Department of Urology, Peking University Shenzhen Hospital, Shenzhen, Guangdong 518036; \\ ${ }^{2}$ Graduate School of Guangzhou Medical University, Guangzhou, Guangdong 510182; ${ }^{3}$ Guangdong \\ Key Laboratory of Male Reproductive Medicine and Genetics, Peking University Shenzhen Hospital, \\ Shenzhen PKU-HKUST Medical Center, Shenzhen, Guangdong 518036, P.R. China
}

Received May 19, 2016; Accepted June 13, 2017

DOI: $10.3892 /$ mco.2017.1526

\begin{abstract}
Multilocular cystic renal cell carcinoma (MCRCC), which exhibits low-stage and low-grade characteristics, is a special type of RCC. MCRCC is extremely rare and generally develops at ages $>50$ years. We herein report a case of MCRCC in a 28-year-old man, which, to the best of our knowledge, is the youngest case reported worldwide to date. The patient presented with irritative bladder symptoms for 1 year. Dynamic enhanced computed tomography (CT) imaging revealed a mass with inhomogeneous enhancement in the left kidney, with a rich blood supply. B-ultrasonography also revealed a renal protruding mass. As the mass was highly suspicious to be a malignant tumor, laparoscopic radical nephrectomy was performed and MCRCC was definitively diagnosed by pathological examination. The patient has been regularly followed up for 6 months, without complications or disease recurrence.
\end{abstract}

\section{Introduction}

Multilocular cystic renal cell carcinoma (MCRCC) was first reported by Perlmann in 1928 and named lymphangiohemangioma (1). MCRCC is a rare entity, comprising $<2 \%$ of all renal carcinomas and it mainly occurs in patients aged 30-80 years (1). Histologically, MCRCC consists of multiple cysts containing old and fresh hemorrhagic material, with clear cells in the septa separating the cysts, which may make

Correspondence to: Professor Liangchao Ni or Professor Yongqing Lai, Department of Urology, Peking University Shenzhen Hospital, 1120 Lianhua Road, Shenzhen, Guangdong 518036, P.R. China E-mail: 13609618222@163.com

E-mail: yqlord@163.com

*Contributed equally

Key words: multilocular cystic renal cell carcinoma, youngest patient, prognosis, pathological type it indistinguishable from clear-cell carcinoma (2). Although MCRCC has non-specific symptoms, it is a tumor of low grade, with low malignant potential; it is curable by surgical resection, either simple nephrectomy or nephron-sparing surgery, and it has a favourable prognosis compared with other types of renal cancer, such as clear-cell and tubulocystic cancer (2). In this study, we present the case of a 28 -year-old male patient, who, to the best of our knowledge, is the youngest MCRCC patient reported to date. This study was approved by the Ethics Committee of Peking University Shenzhen Hospital (Shenhen, China) and written informed consent was obtained from the patient for the publication of the case details.

\section{Case report}

A 28-year-old male patient was admitted to the Department of Urology of Peking University Shenzhen Hospital (Shenzen, China) on May 28, 2015, with the chief complaint of urinary irritant symptoms for 1 year. The patient was a non-smoker, of normal built and normal nutritional status. There was no abdominal pain, no changes in appetite and/or weight variation, and no cardiovascular or respiratory symptoms; he had not undergone any surgery and there was no family history of disease. The patient had a pulse rate of $\sim 84$ beats per min, a temperature of $36.3^{\circ} \mathrm{C}$, a blood pressure of $110 / 73 \mathrm{mmHg}$ and a respiratory rate of 20 breaths per min. Physical examination revealed no positive signs.

Laboratory examination revealed a white blood cell count of $9.59 \times 10^{9} / 1$ and a haemoglobin level of $157 \mathrm{~g} / \mathrm{l}$. The serum glucose level was $6.13 \mathrm{mmol} / \mathrm{l}$, the blood urea nitrogen was $7.03 \mathrm{mmol} / \mathrm{l}$ and the creatinine level was $64.4 \mu \mathrm{mol} / \mathrm{l}$. The blood coagulation parameters and liver function were within the normal range. The chest $\mathrm{X}$-ray revealed no abnormalities. Urinalysis was also normal. A $4.2 \times 4.9-\mathrm{cm}$ round isodense mass (24-41 HU) in the lower pole of the left kidney was identified by a non-contrast CT scan (Fig. 1A), presenting as a heterogeneously enhanced mass (39-64 HU) on contrast-enhanced CT (Fig. 1B).

The patient underwent left radical nephrectomy on June 5,2015 . Invasion of the surrounding tissue was not observed intraoperatively, whereas several cysts of different sizes were 

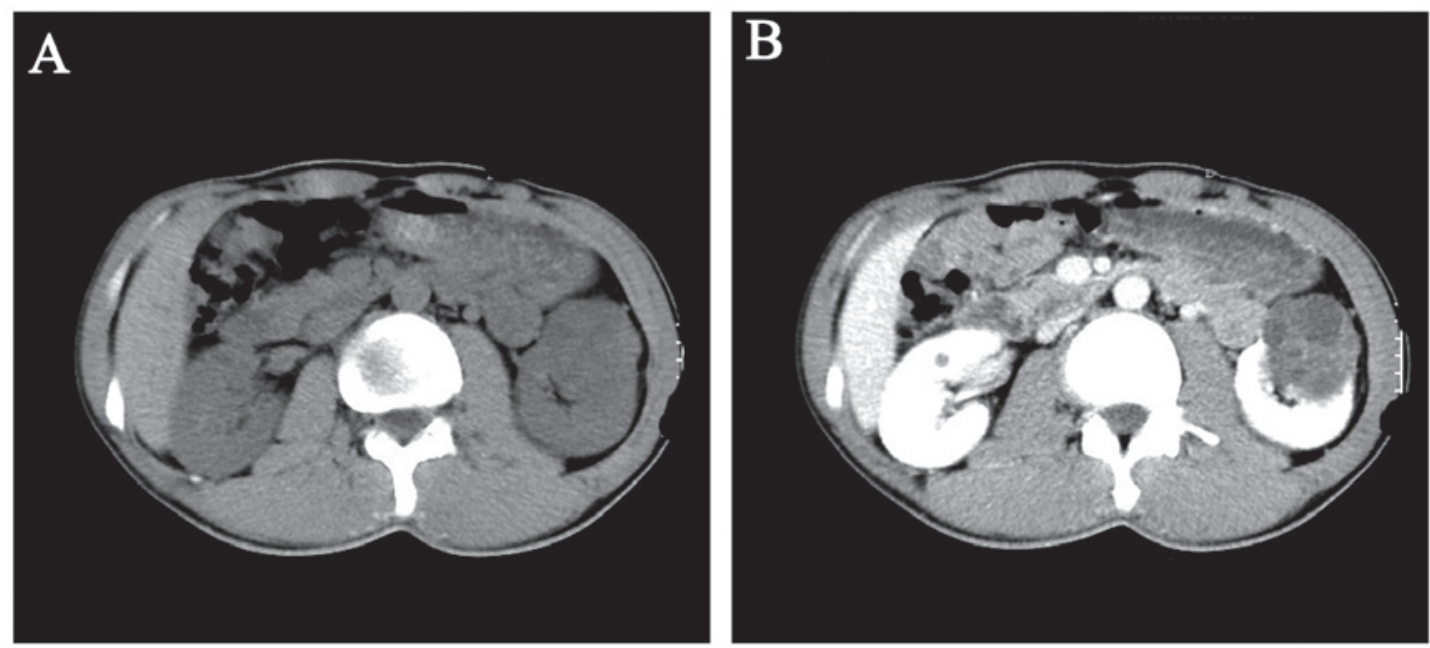

Figure 1. Computed tomography (CT) scan of the kidneys. (A) A 4.2x4.9-cm round isodense mass (24-41 HU) was identified in the lower pole of the left kidney (non-contrast CT). (B) The mass was heterogeneously enhanced (39-64 HU) (contrast-enhanced CT).
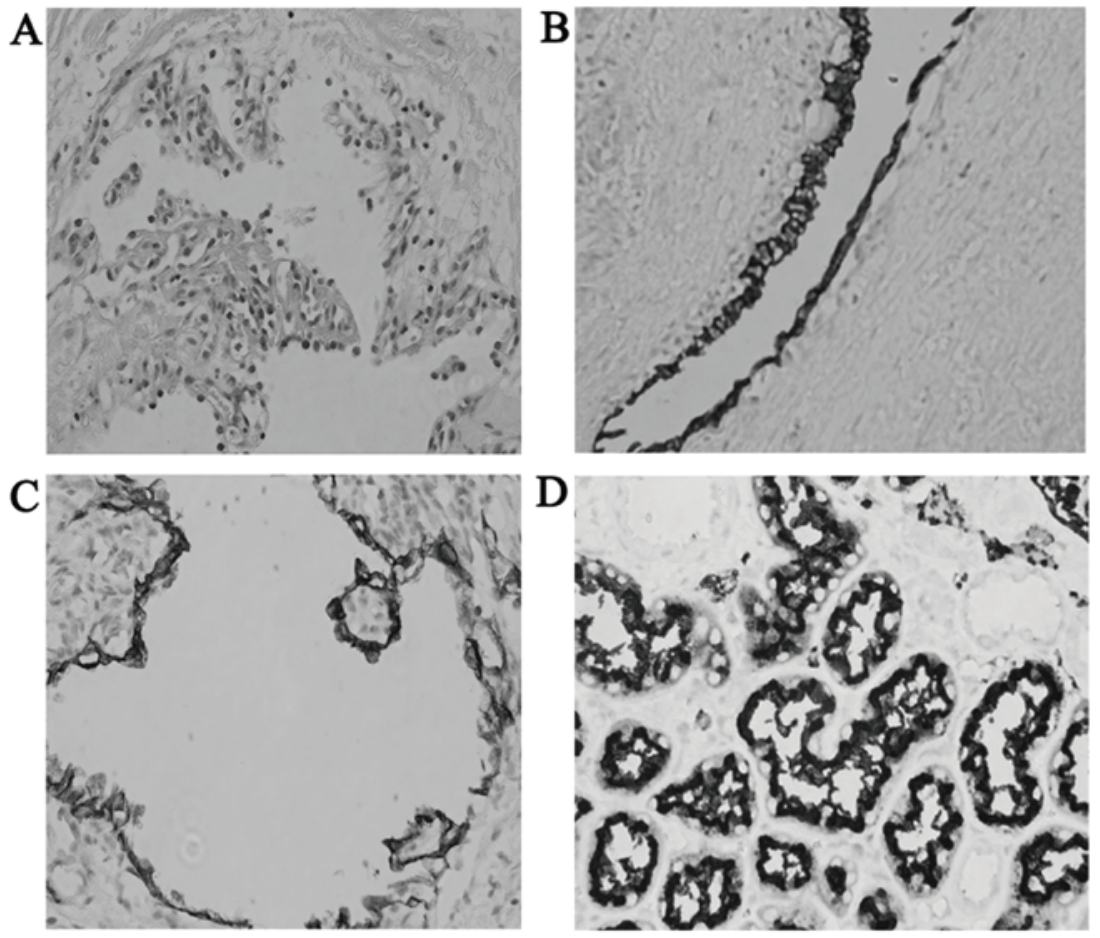

Figure 2. Results of (A) pathological and (B-D) immunohistochemical staining examination. (A) The clear tumor cells adhered to the inner wall of the cyst and their nuclei were significantly hyperchromatic (magnification, $\mathrm{x} 400$; hematoxylin and eosin staining). On immunohistochemical examination, the tumor cells were positive for (B) cytokeratin (CK), (C) CK7 (magnifcation, x100 respectively) and (D) epithelial membrane antigen (magnification, x400).

identified. Grossly, the mass was well-encapsulated. The pathologist observed that the clear tumor cells adhered to the inner wall of the cyst and their nuclei were significantly hyperchromatic (Fig. 2A). Papillary growth was identified partially and the cysts were totally separated by fibrous septae. The immunohistochemical staining examination (Fig. 2B-D) revealed that the tumor cells were positive for cytokeratin (CK), CK7 and epithelial membrane antigen. The final diagnosis was confirmed to be MCRCC, according to the reference standards of the 2004 World Health Organization classification (https://www.iarc.fr/en/publications/pdfs-online/pat-gen/bb7/BB7.pdf) and the recommendations of Ebin and Bonsib (3). Magnetic resonance imaging and sentinel lymph node biopsy revealed no other metastatic lesions.

The patient was discharged on the sixth postoperative day and he had a good recovery. He has since been routinely followed up and remains alive without evidence of recurrence.

\section{Discussion}

MCRCC was reported in the 2004 WHO classification and known to have a favourable prognosis $(4,5)$. MCRCC is a rare type of clear cell RCC, accounting for $2 \%$ of all kidney cancers (2) 
Table I. Previously reported cases of multilocular cystic renal cell carcinoma.

\begin{tabular}{|c|c|c|c|c|c|c|c|}
\hline Case & Authors & Year & Age (years), gender & Size $(\mathrm{cm})$ & Location & Pathological characteristics & (Refs.) \\
\hline 1 & $\begin{array}{l}\text { Wahal } \\
\text { and Mardi }\end{array}$ & 2014 & 55 male & $13 \times 6 \times 3$ & $\begin{array}{l}\text { Middle part } \\
\text { of left kidney }\end{array}$ & $\begin{array}{l}\text { A complex cystic tumor } \\
\text { comprising variably sized } \\
\text { non-communicating cysts } \\
\text { separated by septae containing } \\
\text { tumor cells with uniform, } \\
\text { hyperchromatic nuclei, with } \\
\text { inconspicuous nucleoli }\end{array}$ & (2) \\
\hline 2 & Singhai et al & 2013 & 60 male & $10 \times 12 \times 5$ & Right kidney & $\begin{array}{l}\text { A multilocular, multicystic } \\
\text { tumour mass with cysts } \\
\text { separated by fibrocollagenous } \\
\text { connective tissue lined by a } \\
\text { mixture of cells, including } \\
\text { flattened to cuboidal and clear cells }\end{array}$ & (11) \\
\hline 3 & Deger, et al & 2015 & 53 female & $4 \times 3$ & $\begin{array}{l}\text { Upper pole of } \\
\text { left kidney }\end{array}$ & $\begin{array}{l}\text { Cysts lined with flattened } \\
\text { epithelial cells arranged } \\
\text { in a single row, with a } \\
\text { hobnail appearance }\end{array}$ & (12) \\
\hline 4 & Guo et al & 2011 & 54 male & $2.5 \times 2.3$ & $\begin{array}{l}\text { Lower pole of } \\
\text { right kidney }\end{array}$ & $\begin{array}{l}\text { Triphasic pattern of } \\
\text { blastema, epithelial } \\
\text { and stromal cells }\end{array}$ & (13) \\
\hline 5 & Present study & 2016 & 28 male & $4.2 \times 4.9$ & $\begin{array}{l}\text { Lower pole of } \\
\text { left kidney }\end{array}$ & $\begin{array}{l}\text { The clear tumor cells } \\
\text { adhered to the inner } \\
\text { wall of the cyst and their } \\
\text { nuclei were significantly } \\
\text { hyperchromatic }\end{array}$ & \\
\hline
\end{tabular}

and its prognosis is relatively better compared with that of other malignant kidney tumors (6). The age of patients at diagnosis is $>30$ years, with the mean age $>55$ years $(6,7)$. The morbidity increases gradually with advancing age. It was previously reported that the incidence in men is higher compared with that in women, with a ratio of 3:1 (7). Microscopically,MCRCC, which is pathologically characterized by a single layer of low-grade neoplastic clear cells in its cyst wall, is frequently located in the upper or lower pole of the kidney. The typical clinical characteristics (gross hematuria, flank pain and a palpable mass) closely resemble those of RCC; thus, MCRCC may be misdiagnosed as conventional RCC by less clinically experienced doctors (6). The pathogenesis of MCRCC remains unknown at present, with certain scholars suggesting that intrinsic multilocular cystic growth and papillary cystic adenocarcinoma are strongly associated with the occurrence of this disease. From the perspective of molecular biology, deletions in chromosome $3 p$ may play a significant role in development and progression; these changes have been reported in $80 \%$ of MCRCCs and are closely associated with a worse result (8). Another cancer suppressor gene, referred to as the Von Hippel-Lindau gene, which is located in the 3p25 chromosomal area, has a major effect on carcinogenesis (9).

To the best of our knowledge, elderly patients presenting with indolent gross hematuria may suffer from urinary tract tumors. Contrast-enhanced CT is required for such patients to detect highly vascular renal parenchymal tumors. The CT attenuation values of benign tumors is generally $<15 \mathrm{HU}$ (10). However, patients with enhanced lesions ( $>39$ HU) are highly suspicious for RCC. We must bear in mind that CT cannot reliably confirm the diagnosis of MCRCC, and pathological confirmation is always required.

Since the primary characteristics of MCRCC are low grade and stage, the outcome is generally favorable. The majority of previously published cases were stage I and surgical resection was timely performed. Tumor size was not found to be associated with patient survival time (5).

\section{Acknowledgements}

The present study was supported by Science and Technology Development Fund Project of Shenzhen (grant nos. JCYJ20150403091443329 and JCYJ20170307111334308), the fund of 'San-ming' Project of Medicine in Shenzhen (SZSM201612066), and the fund of Guangdong Key Medical Subject.

\section{References}

1. Cheng L and Huang W: Multilocular cystic clear cell neoplasm of low malignant potential: Evolving concept, classification and unifying terminology. Zhonghua Bing Li Xue Za Zhi 43: 721-722, 2014 (In Chinese).

2. Wahal SP and Mardi K: Multilocular cystic renal cell carcinoma: A rare entity with review of literature. J Lab Physicians 6: 50-52, 2014. 
3. Ebin JN and Bonsib SM: Extensively cystic renal neoplasms: Cystic nephroma, cystic partially differentiated nephroblastoma, multilocular cystic renal cell carcinoma, and cystic hamartoma of renal pelvis. Semin Diagn Pathol 15: 2-20, 1998.

4. Williamson SR, MacLennan GT, Lopez-Beltran A, Montironi R, Tan PH, Martignoni G, Grignon DJ, Eble JN, Idrees MT, Scarpelli $M$ and Cheng L: Cystic partially regressed clear cell renal cell carcinoma: A potential mimic of multilocular cystic renal cell carcinoma. Histopathology 63: 767-779, 2013.

5. Tamura Y, Okamura K, Ogura H, Kawada T, Tsuji H, Takahashi Y, Fukabori Y, Kobayashi M, Imai K and Yamanaka H: Multilocular cystic renal cell carcinoma: A report of 2 cases. Hinyokika Kiyo 36: 437-441, 1990 (In Japanese).

6. Ghosh P and Saha K: Multilocular cystic renal cell carcinoma: A rare, unique entity and diagnostic challenge. Arch Iran Med 17: 129-132, 2014

7. Chowdhury AR, Chakraborty D, Bhattacharya P and Dey RK: Multilocular cystic renal cell carcinoma a diagnostic dilemma: A case report in a 30-year-old woman. Urol Ann 5: 119-121, 2013.

8. Yamaguchi S, Yoshihiro S, Matsuyama H, Nagao K, Fukunaga K Matsumoto H, Matsuda K, Oba K and Naito K: The allelic loss of chromosome 3p25 with c-myc gain is related to the development of clear-cell renal cell carcinoma. Clin Genet 63: 184-191, 2003.

9. Halat SK and MacLennan GT: Multilocular cystic renal cell carcinoma. J Urol 177: 343, 2007.
10. Imura J, Ichikawa K, Takeda J, Tomita S, Yamamoto $\mathrm{H}$, Nakazono M, Takimoto T, Ueda Y and Fujimori T: Multilocular cystic renal cell carcinoma: A clinicopathological, immuno- and lectin histochemical study of nine cases. APMIS 112: 183-191, 2004.

11. Singhai A, Babu S, Verma N and Singh V: Multilocular cystic renal cell carcinoma: A rare entity. BMJ Case Rep 2013: pii: bcr2012008457, 2013

12. Deger AN, Capar E, Ucar BI, Deger H and Tayfur M: Adult multicystic nephroma: Case report and review of the literature. J Clin Diagn Res 9: ED22-ED23. 2015.

13. Guo A, Wei L, Song X and Liu A: Adult wilms tumor with intracaval and intracardiac extension: Report of a case and review of literature. J Cancer 2: 132-135, 2011. 